DOI: $10.1002 /(($ please add manuscript number $))$

Article type: Communication

\title{
3D Macroporous Solids from Chemically Cross-linked Carbon Nanotubes
}

\author{
Sehmus Ozden ${ }^{1}$, Tharangattu N. Narayanan ${ }^{2}$, Chandra S. Tiwary ${ }^{1}$, Pei Dong $^{1}$, Amelia H. C. \\ Hart $^{1},{ }_{-}$Robert Vajtai ${ }^{1}$, Pulickel M. Ajayan ${ }^{1 *}$
}
S. Ozden, Dr. C. S. Tiwary, Dr. P. Dong, A. H. C. Hart, Dr. R. Vajtai, Prof. P. M. Ajayan Department of Material Science and NanoEngineering Rice University
Houston, Texas 77005, USA
E-mail: ajayan@rice.edu
Dr. T. N. Narayanan
CSIR-Central Electrochemical Research Institute
Karaikudi, 630006, India

\section{*Corresponding Author: ajayan@ rice.edu}

KEYWORDS: Carbon nanotubes, chemical cross-linking, Suzuki reaction, three-dimensional, Palladium

If carbon nanotubes (CNTs) could be controllably interconnected, new types of 3D macroscopic carbon solids could be created with novel properties. The creation of such nanoengineered 3D architectures remains one of the most impotant challenges in nanotechnology. Production of nanoengineered 3D carbon structures, with controlled density and architecture, is one of the most desirable step for building next generation carbon based functional materials [1-3]. Current forms of CNT-based macrostructures include aligned CNTs [4], fibers [5], buckypapers [6,7], and aerogels [8, 9], each with different potential application areas such as supercapacitors [10,11], catalytic electrodes [12], dry adhesion [13], artificial muscles [14], gas adsorbers [15] and environmental applications [2, 16]. However, true 3D structures with covalent interconnections between building blocks such as CNT or graphene, are still challenging. For the inexpensive mass production and selectivity of 3DCNT solid structures, chemical functionalization and cross-linking could be one of the most 


\section{WILEY-VCH}

controllable and scalable methods. Creating covalent junctions between CNTs is one of the most crucial steps to build CNT-based 3D macroscopic architectures [17]. Recently, there have been a few efforts to build such covalently interconnected 3D-CNT building blocks using chemical vapor deposition (CVD) technique [2, 3, 18] and solution chemistry [19, 20]. To create 3D-CNT based macro-architectures via solution chemistry, surface modification is one of the fundamental requirements. The essentials of chemical functionalization approach to create CNT frameworks rely on organic bridges which are bonded to CNTs and this approach has been used by several groups during the last decade [19, 21-23]. In these reports, CNT materials were produced using chemical functionalization, consisting of bonds with functional groups such as amines.

The Suzuki cross-coupling reaction, which is one of the most popular synthetic routes to create carbon-carbon (C-C) covalent junctions, has been used in a variety of real world synthetic applications. Some of which are the synthesis of natural products [24] and the formation of materials for energy and electronics [25]. It is a general method for creating carbon-carbon single covalent bonds between organic halides and boronic acid derivatives using Pd-based catalysts. Previously this crucial method has been used by Cheng and Adronov for the surface functionalization of CNTs [26]. Here, we report the scalable synthesis of 3D macroscopic solids made of covalently connected nanotubes via Suzuki crosscoupling (Figure 1). The resulting CNT solids are made of highly porous, interconnected structures made of chemically cross-linked carbon nanotubes. The CNT solids represent the next generation of carbon materials with several potential applications; we demonstrate here one such utility in the removal of oil from contaminated water [2, 3]. Raman spectroscopy (633nm laser), X-ray photoelectron spectroscopy (XPS), scanning electron microscope (SEM)(SEM, FEI Quanta 400 ESEM FEG), transmission electron microscope (TEM)(JEOL 2100 Field Emission Gun TEM), and low temperature nitrogen absorbtion Quantachrome 


\section{WILEY-VCH}

$\underline{\text { Autosorb-3B }}$ BET surface analyzer and thermogravimetric analysis (TGA) were used as characterization tools.

The Suzuki cross-coupling reaction occurs between aryl halide and boronic acid derivatives. The reaction mechanism of the CNT interconnection using Suzuki cross-coupling reaction is shown in figure 2. Firstly, the CNTs_(Cheap tubes inc., 20-30 nm outer diameter, 10-30 $\mu \mathrm{m}$ length) were refluxed in concentrated $\mathrm{HNO}_{3}$ for 18 hours to produce shortened and oxidized CNTs with oxygen-containing groups, the majority of which contain carboxyl groups (1) [27]. This oxidative procedure is also necessary to remove unwanted amorphous carbon and other residual metal impurities [28, 29]. Then, the carboxyl groups (CNT-COOH) (1) were converted to the corresponding acid chloride $(\mathrm{CNT}-\mathrm{COCl})$ by reacting with $\mathrm{SOCl}_{2}$ at $80{ }^{\circ} \mathrm{C}$ for $24 \mathrm{~h}$ (2). Tetrakis(triphenylposphine) palladium( $(0)\left(\mathrm{Pd}\left(\mathrm{PPh}_{3}\right)_{4}\right)$ was added under argon to a mixture of 1,4-phenyldiboronic acid and anhydrous $\mathrm{Cs}_{2} \mathrm{CO}_{3}$ in anhydrous toluene followed by CNT-COCl (2). The reaction mixture was then heated at $100{ }^{\circ} \mathrm{C}$ for 5 days. The resulting material was filtered and washed with water to remove excess $\mathrm{Cs}_{2} \mathrm{CO}_{3}$ and unreacted 1,4phenyldiboronic acid. The reaction mechanism starts with the oxidative addition of CNT$\mathrm{COCl}$ (2) to the $\mathrm{Pd}(0)$ to form a $\mathrm{Pd}(\mathrm{II}), \mathrm{CNT}-\mathrm{CO}-\mathrm{Pd}-\mathrm{Cl}$ (3), complex structure; after which the base, $\mathrm{Cs}_{2} \mathrm{CO}_{3}$, replaces the chloride on the palladium complex. Transmetallation starts with adding 1,4-benzenediboronic acid. Then the reductive elimination gives the boronic acid functional CNTs $\left(\mathrm{CNT}-\mathrm{CO}-\mathrm{Ph}-\mathrm{B}(\mathrm{OH})_{2}\right)$ (5). After repeating the same mechanism between boronic acid functionalized CNTs and chlorinated CNTs (CNT-COCl) (2) the final CNT-COPh-CO-CNT (6) coupling product was formed.

To create junctions between CNTs using solution chemistry, surface modification of CNT is necessary. The modifications of the surface of the CNTs are confirmed using Raman spectroscopy [30] (figure 3a). Raman spectra of CNTs typically has two peaks, the G-band which is closely related to vibrations of $\mathrm{sp}^{2}$ carbon materials, and the D-band which comes from the disorder of CNT sidewalls [31]. A quantitative measure of defect density in the CNT 


\section{WILEY-VCH}

sidewalls can be determined from the ratio between these two bands, $\mathrm{I}_{\mathrm{D}}: \mathrm{I}_{\mathrm{G}}$. This ratio is used for obtaining information about the structural changes as a result of functionalization $[32,33]$. The Raman spectra of these CNTs show a disorder mode (D-band) and graphitic mode (Gband) at $1349 \mathrm{~cm}^{-1}$ and $1571 \mathrm{~cm}^{-1}$ respectively. As a result of functionalization, the intensity of the D-band increases due to $\mathrm{sp}^{3}$ carbons in the CNTs after acid treatment $[34,35]$. The intensity ratio between the D-band and G-band $\left(\mathrm{I}_{\mathrm{D}} / \mathrm{I}_{\mathrm{G}}\right)$ increased from 0.59 to 1.06 because the disorder on the surface of CNTs increased $[34,36]$.

XPS analysis was used for quantitative chemical analysis of the pure, chlorinated, and crosslinked CNTs (figure 3). The $\mathrm{C} 1 \mathrm{~s}$ core level peak positions of the carbon atoms are approximately at $285 \mathrm{eV}$ and the peak position of oxygen is around $532 \mathrm{eV}$. After oxidation of CNTs the ratio of oxygen increased from $1.2 \%$ to $11 \%$. In high resolution XPS characterization of pure $\mathrm{CNTs}$, the $\mathrm{C}-\mathrm{C}$ and $\mathrm{O}-\mathrm{C}=\mathrm{O}$ bond peak is at 284.6 and $284.8 \mathrm{eV}$ respectively (figure 3b ). In the XPS spectrum of the chlorinated CNTs, the peak around 200 $\mathrm{eV}$ represents chlor $(\mathrm{Cl})$ atom (figure 3c). The peaks at $284.4 \mathrm{eV}, 285 \mathrm{eV}$ and $285.9 \mathrm{eV}$ correspond $\mathrm{C}-\mathrm{C}, \mathrm{O}-\mathrm{C}=\mathrm{O}$ and $\mathrm{C}-\mathrm{Cl}$ bonds respectively in figure $2 \mathrm{c}$. According to the survey scan of XPS characterization the amount of chlorine constitutes $1.4 \%$ by weight of the sample. Figure 3d shows the XPS spectrum of the CNTs after the Suzuki cross-coupling reaction where $\mathrm{C}-\mathrm{C}, \mathrm{C}=\mathrm{O}$ and $\mathrm{C}-\mathrm{O}$ bonds are at $284.5 \mathrm{eV}, 284.9 \mathrm{eV}$ and $285.8 \mathrm{eV}$ respectively. Chlorine atoms disappear after the Suzuki cross-coupling reaction as shown in figure $3 \mathrm{~d}$. These peaks are indicate that the coupling reaction took place successfully. Apart from the spectroscopy characterizations the junctions were imaged using scanning electron microscopy (SEM) as well as transmission electron microscopy (TEM).

BET surface analyzis was used to determine the surface area and porosity of the pristine CNTs and the 3D-CNT solids. Freeze dried pristine CNT and 3D-CNT solids were degassed 17 hours at $200{ }^{\circ} \mathrm{C}$, then BET surface analyzis carried out. The $\mathrm{N}_{2}$ absorption shows a -type-II isotherm that exhibits a negligible concave section, that is -known to be pointed to 


\section{WILEY-VCH}

microporous volume uptake and a quick ascent in total volume close $\mathrm{P} / \mathrm{P}_{0}=1$ indicating a macroporous material (Figure S6a). The BET surface area $\left(\mathrm{S}_{\mathrm{BET}}\right)$ area of 3D-CNT solids (177 $\mathrm{m}^{2} / \mathrm{g}$ ) is larger than the one for the pristine CNTs $\left(166 \mathrm{~m}^{2} / \mathrm{g}\right.$ ) (Figure S6b). CNT and 3D-CNT solid have similar average pore size distribution and the cummulative pore volume of 3DCNT solid is higher than CNTs. (Figure S6c).

The structure of the 3D-CNT macrostructure is shown in figure 4. A few conditions such as oxidation rate, reaction time, and different ratios of the initial materials were varied during the experiment. The best results were obtained from 18 hours of oxidation in $\mathrm{HNO}_{3}$ and at least 5 days reaction time of the Suzuki coupling reaction due to increased functionalization ratio. These longer oxidation and Suzuki coupling times enable the CNTs to form 3D solid macrostructures after lyophilization (freeze-drying) due to higher CNT cross-coupling ratios. CNTs were found to form a solid macrostructure when they have enough functional groups to cross-link with covalent interconnection. The image of a 3D-CNT solid network is shown in figure $4 \mathrm{~g}$ which contains various network morphologies in different regions. The 3D-CNT solid structure is highly porous as can be seen in figure $4 \mathrm{c}$. In the morphology of the solid structure observed in figure $4 \mathrm{c}, \mathrm{CNT}$ bundles are interconnected as a network, creating the microporous structures. The other morphology is observed in figure $4 \mathrm{a}$ and $4 \mathrm{~d}$ where the CNTs form a layer by layer assembly, into thin films. Additionally, CNTs can also be formed into macrotubular architectures (Figure 4e). Cross-coupling of the CNTs can be observed in the SEM images included in figure S3 of the supporting information. The low magnification image in figure S3 reveals interconnections between CNTs. These Y-junctions of CNTs can be either end-to-side or end-to-end junctions which as a result of the oxidation step, where the ends of CNTs and the surfaces of CNTs were oxidized. TEM was used to obtain more detailed morphological information of the CNT junctions, shown in figure 5. In order to confirm the presence of the CNT junctions, bright field images were obtained. It was further found that linkers with different shapes yield CNTs with more complex architectures 


\section{WILEY-VCH}

compared to simple junction geometries (figure 5a). Figure 5b shows multi-terminal CNT junctions and their representative schematic figure is shown on the bottom of TEM images. In general it has been observed that the end-to-end junctions are more prevalent than other types of junctions, due to the ends of nanotubes being preferentially modified. The ends of the CNTs are chemically more reactive than their sides because of the presence of defects at these sites (figure S4).The TEM images of X-junction CNTs that have been formed as a result of side-to-side functionalization are shown in figure 5c. All these types of junctions are essential for the CNTs to form solid structures.

Recent reports have proven that one of the potential applications of such porous CNT solids is in oil absorption from water since these are typically oleophilic. Following some of the previous reports on the oil absorption capacity of vapor grown 3D-CNT solids, the 3D-CNT solids made here by chemical cross-linking were demonstrated for the same application. The absorbed oil (used engine oil) has been shown to be removed easily by burning the material in air without destroying the structure. The 3D-CNT solid material obtained in this study absorbed 120 times its own weight of oil within four minutes (Figure \$6).

In conclusion, we have reported the well-known Suzuki cross-coupling reaction as an approach to create covalently bonded CNT networks. As a consequence of the cross-linking of the CNTs, the formation of highly porous 3D solids occured. Additionally, multi-terminal junctions of CNTs in end-to-end, end-to-side and side-to-side configurations were observed in the microstructure,also as a result of the cross linking. The approach demonstrates the ability to interconnect nanostructures such as carbon nanotubes using interface controllable chemistry that can lead to scalablesynthesis of 3D solids with controlled morphologies and multifunctional properties.

\section{Experimental Section}




\section{WILEY-VCH}

Synthesis of covalently interconnected 3D-CNT solids: CNTs (12 mg) were refluxed in concentrated $\mathrm{HNO}_{3}$ for 18 hours to produce shortened and oxidized CNTs, which have terminal, mainly carboxyl, oxygen-containing groups,. The oxidized CNTs were then washed with DI-water until $\mathrm{pH}=7$. Then CNTs were refluxed in $50 \mathrm{ml} \mathrm{SOCl}_{2}$ and $2 \mathrm{ml} \mathrm{1,2-}$ dichlorobenzene for 24 hours. The CNTs were sonicated for $10 \mathrm{~min}$ and added to a flask. Next, $60 \mathrm{mg} \mathrm{Pd}\left(\mathrm{PPh}_{3}\right)_{4}$ and $160 \mathrm{mg} \mathrm{Cs} \mathrm{CO}_{3}$ in toluene $(30 \mathrm{ml})$ were added to said flask. The reaction was run at $100{ }^{\circ} \mathrm{C}$, for 5 days under Ar atmosphere. Then the final product freeze dried.

\section{Supporting Information}

Supporting Information is available from the Wiley Online Library or from the author.

\section{Acknowledgments}

This work has been supported by U.S. Department of Defense: U.S. Air Force Office of Scientific Research (AFOSR) for the project "MURI: Synthesis and Characterization of 3-D Carbon Nanotube Solid Networks" through the award \# FA9550-12-1-0035.

\section{REFERENCES}

[1] P. M. Ajayan, O. Z. Zhou, Top. Appl. Phys. 2001, 80, 391.

[2] D. P. Hashim, N. T. Narayanan, J. M. Romo-Herrera, D. A. Cullen, M. G. Hahm, P. Lezzi, J. R. Suttle, D. Kelkhoff, E. Munoz-Sandoval, S. Ganguli, A. K. Roy, D. J. Smith, R. Vajtai, B. G. Sumpter, V. Meunier, H. Terrones, M. Terrones,P. M. Ajayan, Sci. Rep. 2012, 2, 363.

[3] X. C. Gui, J. Q. Wei, K. L. Wang, A. Y. Cao, H. W. Zhu, Y. Jia, Q. K. Shu, D. H. Wu, Adv. Mater. 2010, 22, 617.

[4] A. Y. Cao, P. L. Dickrell, W. G. Sawyer, M. N. Ghasemi-Nejhad, P. M. Ajayan, Science 2005, 310, 1307.

[5] Y. L. Li, I. A. Kinloch, A. H. Windle, Science 2004, 304, 276. 


\section{WILEY-VCH}

[6] M. Endo, H. Muramatsu, T. Hayashi,Y. A. Kim, M. Terrones, N. S. Dresselhaus, Nature 2005, 433, 476.

[7] S. M. Cooper, H. F. Chuang, M. Cinke, B. A. Cruden, M. Meyyappan, Nano Lett. 2003, 3, 189.

[8] J. H. Zou, J. H. Liu, A. S. Karakoti, A. Kumar, D. Joung, Q. A. Li, S. I. Khondaker, S. Seal, L. Zhai, Acs Nano 2010, 4, 7293.

[9] M. B. Bryning, D. E. Milkie, M. F. Islam, L. A. Hough, J. M. Kikkawa, A. G. Yodh, Adv. Mater. 2007, 19, 661.

[10] D. N. Futaba, K. Hata, T. Yamada, T. Hiraoka, Y. Hayamizu, Y. Kakudate, O. Tanaike, H. Hatori, M. Yumura, S. Iijima, Nat Mater 2006, 5, 987.

[11] Y. W. Cheng, S. T. Lu, H. B. Zhang, C. V. Varanasi, J. Liu, Nano Lett. 2012, 12, 4206.

[12] J. E. Trancik, S. C. Barton, J. Hone, Nano Lett. 2008, 8, 982.

[13] L. T. Qu, L. M. Dai, M. Stone, Z. H. Xia, Z. L. Wang, Science 2008, 322, 238.

[14] J. Foroughi, G. Spinks, G. G. Wallace, J. Oh, M. E. Kozlov, S. L. Fang, T. Mirfakhrai, J. D. W. Madden, M. K. Shin, S. J. Kim, R. H. Baughman, Science 2011, 334, 494.

[15] P. M. Sudeep, T. N. Narayanan, A. Ganesan, M. M. Shaijumon, H. Yang, S. Ozden, P. K. Patra, M. Pasquali, R. Vajtai, S. Ganguli, A. K. Roy, M. R. Anantharaman, P. M. Ajayan, Acs Nano 2013, 7, 7034.

[16] A. Srivastava, O. N. Srivastava, S. Talapatra, R. Vajtai, P. M. Ajayan, Nat. Mater. 2004, 3,610 .

[17] J. M. Romo-Herrera, M. Terrones, H. Terrones, S. Dag, V. Meunier, Nano Lett. 2007, 7, 570 .

[18] C. S. Shan, W. J. Zhao, X. L. Lu, D. J. O'Brien, Y. P. Li, Z. Y. Cao, A. L. Elias, R. Cruz-Silva, M. Terrones, B. Q. Wei, J. Suhr, Nano Lett. 2013, 13, 5514.

[19] A. D. Leonard, J. L. Hudson, H. Fan, R. Booker, L. J. Simpson, K. J. O'Neill, P. A. Parilla, M. J. Heben, M. Pasquali, C. Kittrell, J. M. Tour, J. Am. Chem. Soc. 2009, 131, 723.

[20] Y. C. Zhang, A. A. Broekhuis, M. C. A. Stuart, T. F. Landaluce, D. Fausti, P. Rudolf, F. Picchioni, Macromolecules 2008, 41, 6141.

[21] J. W. Zhang, D. Z. Jiang, Compos. Sci. Technol. 2011, 71, 466.

[22] P. W. Chiu, G. S. Duesberg, U. Dettlaff-Weglikowska, S. Roth, Appl. Phys. Lett. 2002, 80,3811 .

[23] M. Palma, W. Wang, E. Penzo, J. Brathwaite, M. Zheng, J. Hone, C. Nuckolls, S. J. Wind, J. Am. Chem. Soc. 2013, 135, 8440. 


\section{WILEY-VCH}

[24] S. R. Chemler, D. Trauner, S. J. Danishefsky, Angew. Chem. Int.Ed. 2001, 40, 4544.

[25] F. Naso, F. Babudri, G. M. Farinola, Pure Appl. Chem. 1999, 71, 1485.

[26] F. Y. Cheng, A. Adronov, Chem. Mater. 2006, 18, 5389.

[27] I. D. Rosca, F. Watari, M. Uo, T. Akaska, Carbon 2005, 43, 3124.

[28] Z. W. Wang, M. D. Shirley, S. T. Meikle, R. L. D. Whitby, S. V. Mikhalovsky, Carbon 2009, 47, 73 .

[29] H. Hu, B. Zhao, M. E. Itkis, R. C. Haddon, J. Phys. Chem. B 2003, 107, 13838.

[30] R. Graupner, J. Raman Spectrosc. 2007, 38, 673.

[31] M. S. Dresselhaus, G. Dresselhaus, R. Saito, A. Jorio, Phys. Rep. 2005, 409, 47.

[32] C. D. Doyle, J. D. R. Rocha, R. B. Weisman, J. M. Tour, J. Am. Chem. Soc. 2008, 130, 6795.

[33] M. S. Strano, C. A. Dyke, M. L. Usrey, P. W. Barone, M. J. Allen, H. W. Shan, C.

Kittrell, R. H. Hauge, J. M. Tour, R. E. Smalley, Science 2003, 301, 1519.

[34] Z. H. Qu, G. J. Wang, J.Nanosci. Nanotechno. 2012, 12, 105.

[35] H. Z. Geng, K. K. Kim, K. P. So, Y. S. Lee, Y. Chang, Y. H. Lee, J. Am. Chem. Soc. 2007, 129, 7758 .

[36] V. Datsyuk, M. Kalyva, K. Papagelis, J. Parthenios, D. Tasis, A. Siokou, I. Kallitsis, C. Galiotis, Carbon 2008, 46, 833. 


\section{WILEY-VCH}

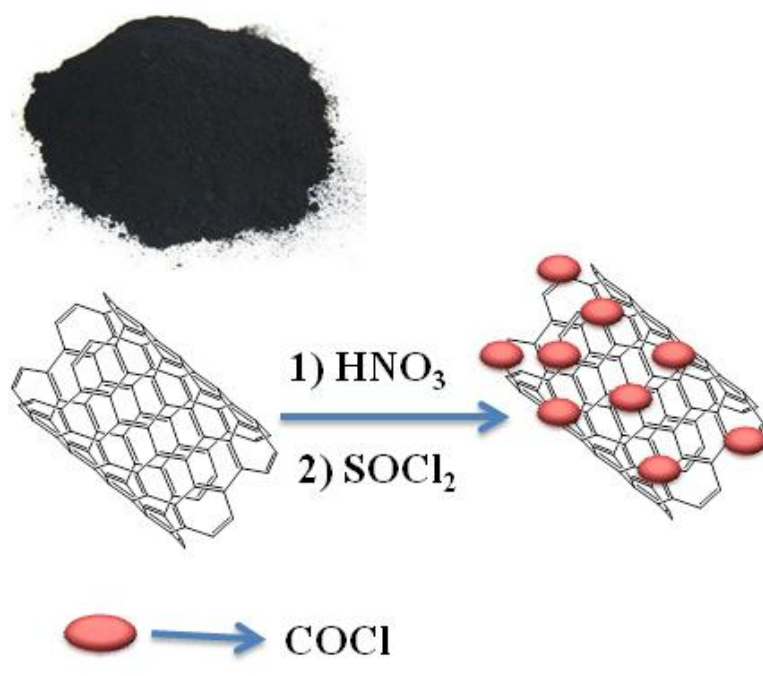

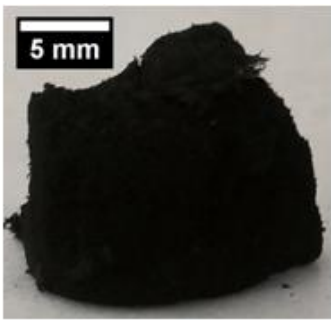

Figure 1. Schematic of the 3D-CNT solid macrostructure synthesis from CNT powder. Initial CNT powder were oxidized in $\mathrm{HNO}_{3}$ then converted to acid chloride. CNTs were covalently interconnected via Suzuki coupling reaction which is palladium catalyst based coupling reaction. After lyophilization (Freeze Drying) 3D-CNT solid structure formed. 


\section{WILEY-VCH}

(1)

(2)

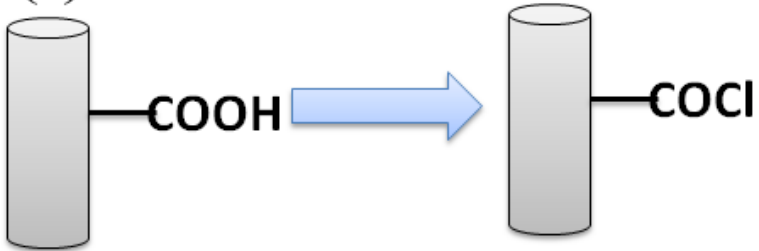

(5)

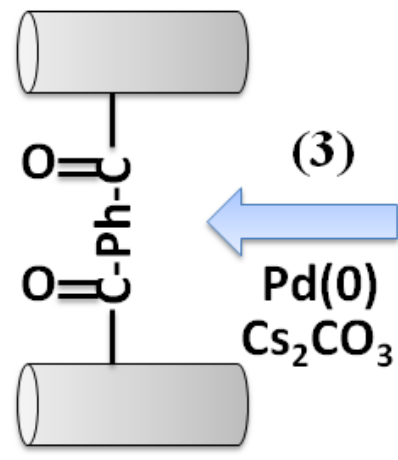

(6)<smiles>C=CC(CC)C(=O)[Pb]O</smiles>

$\mathrm{CO}-\mathrm{Ph}-\mathrm{B}(\mathrm{OH})_{2}$

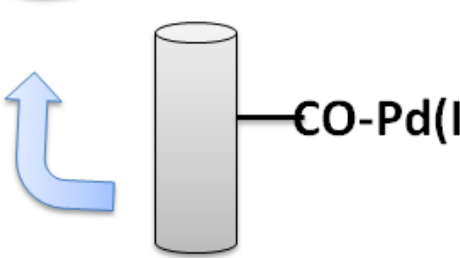

(4)
(3)

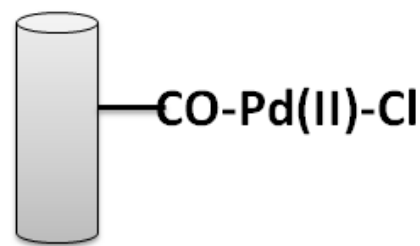

$\operatorname{Pd}(0)$

Figure 2. The Suzuki coupling reaction mechanism. (1) oxidized CNTs, (2) chlorinated CNTs, (3) CNT-CO-Pd(II)-Cl complex structure, (4)CNT-Pd(II)-Ph-B(OH) 2 , (5) boronic acid functionalized CNTs, (6) interconnected CNTs. 

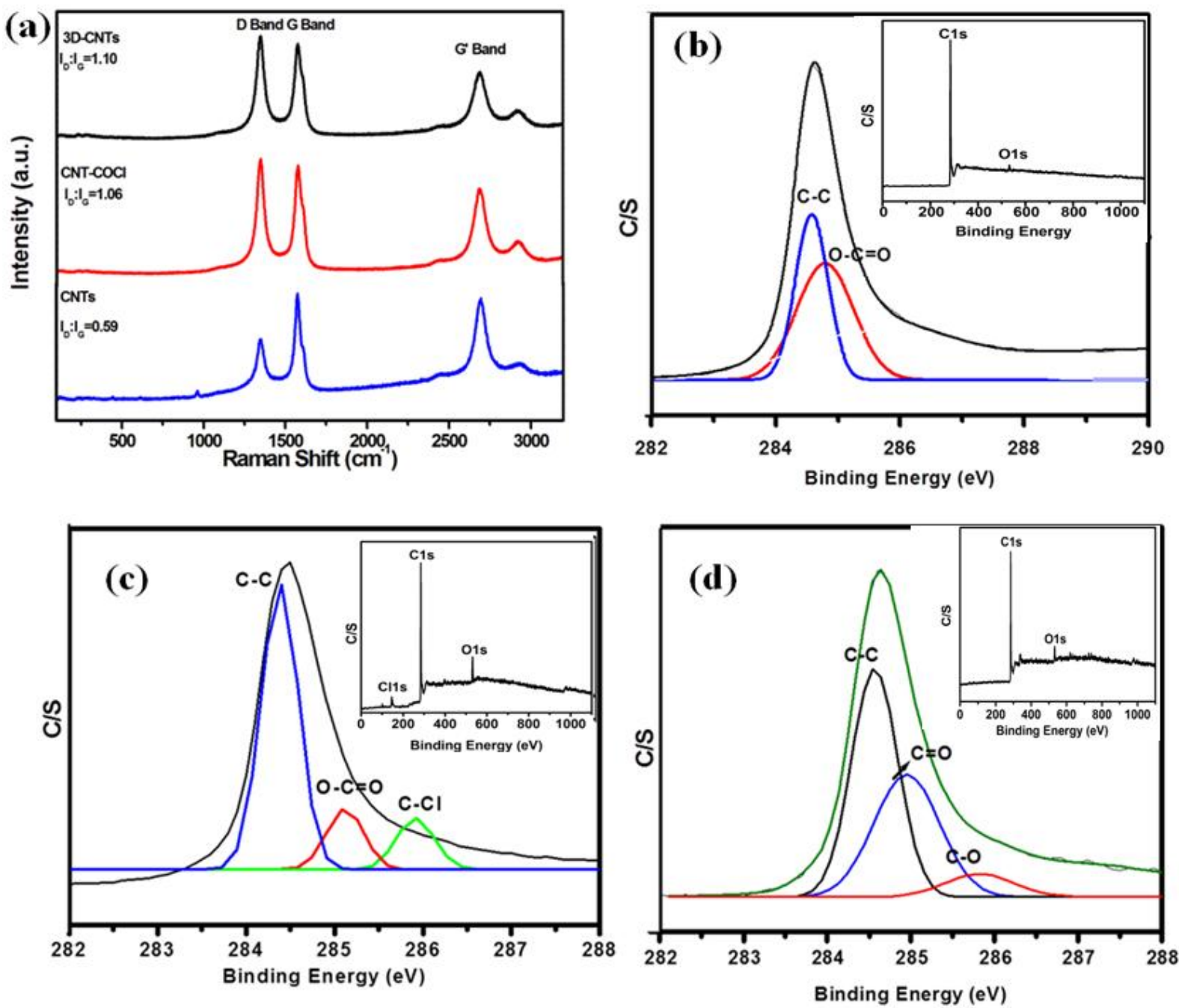

Figure 3. (a) Raman spectra of pristine CNTs powder, chlorinated CNTs and 3D-CNT solid macrostructure, (b) XPS spectra of pristine CNTs powder, (c) chlorinated CNTs powder, (d) 3D-CNT solid macrostructure. 


\section{WILEY-VCH}

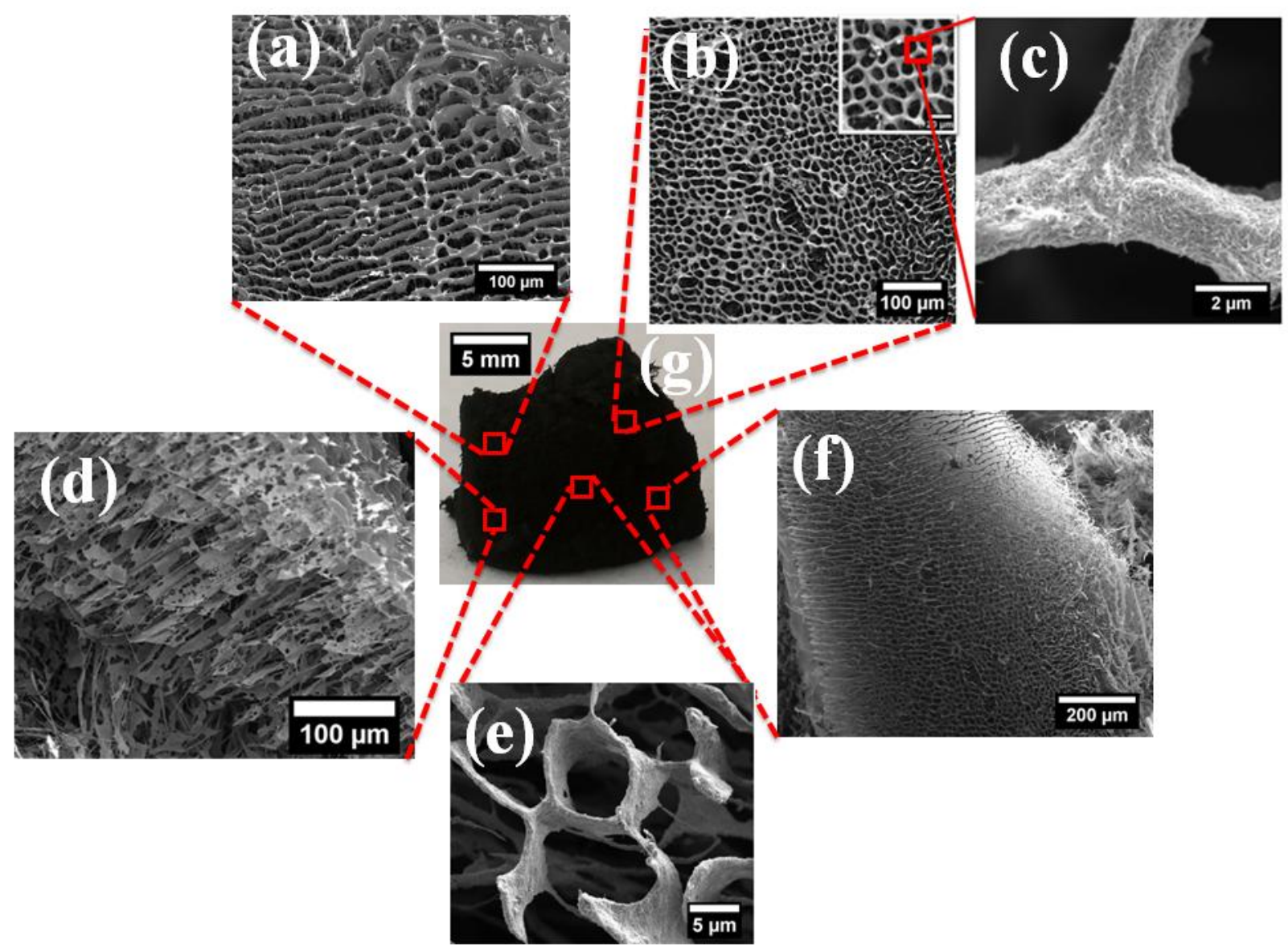

Figure 4. Scanning electron microscopy (SEM) images of different region of the porous 3DCNT solid structure. (a, d) layer by layer CNT thin films, (b, c, f) CNT bundles as a network, (e) 3D-CNT after lyophilization of the covalently connected CNTs via Suzuki coupling reaction formed as tubular structure, (g) 3D-CNT solid macrostructure.
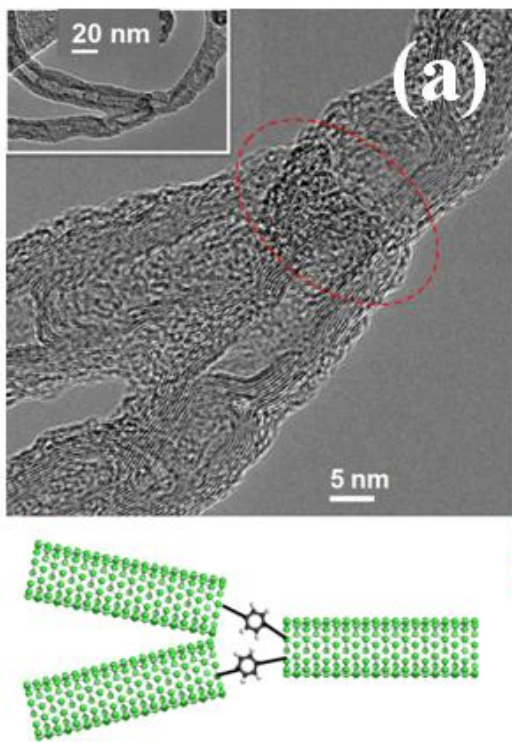
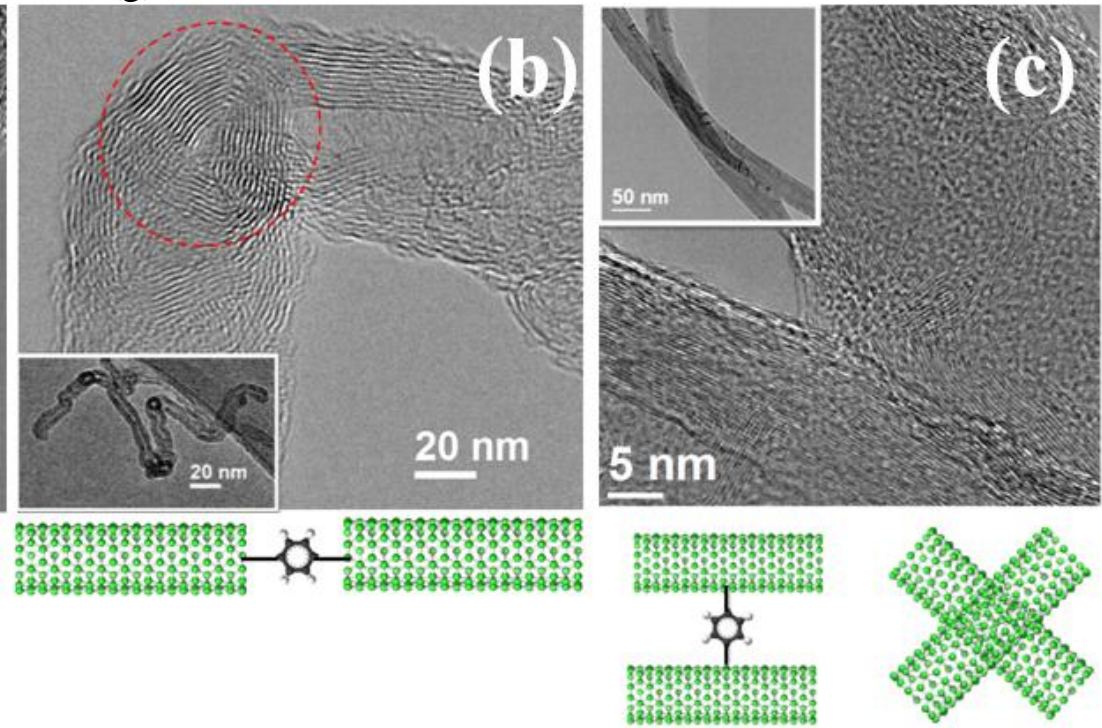

Figure 5. High resolution transmission electron microscopy (HR-TEM) of the 3D-CNT structures, (a) high and low (inserted) magnification image of Y-junction of CNTs with representative schematic image, (b) high and low (inserted) magnification image of end-toend junction of CNTs with representative schematic image (c) high and low (inserted) magnification image of X-junction CNTs with representative schematic image. 


\section{WILEY-VCH}
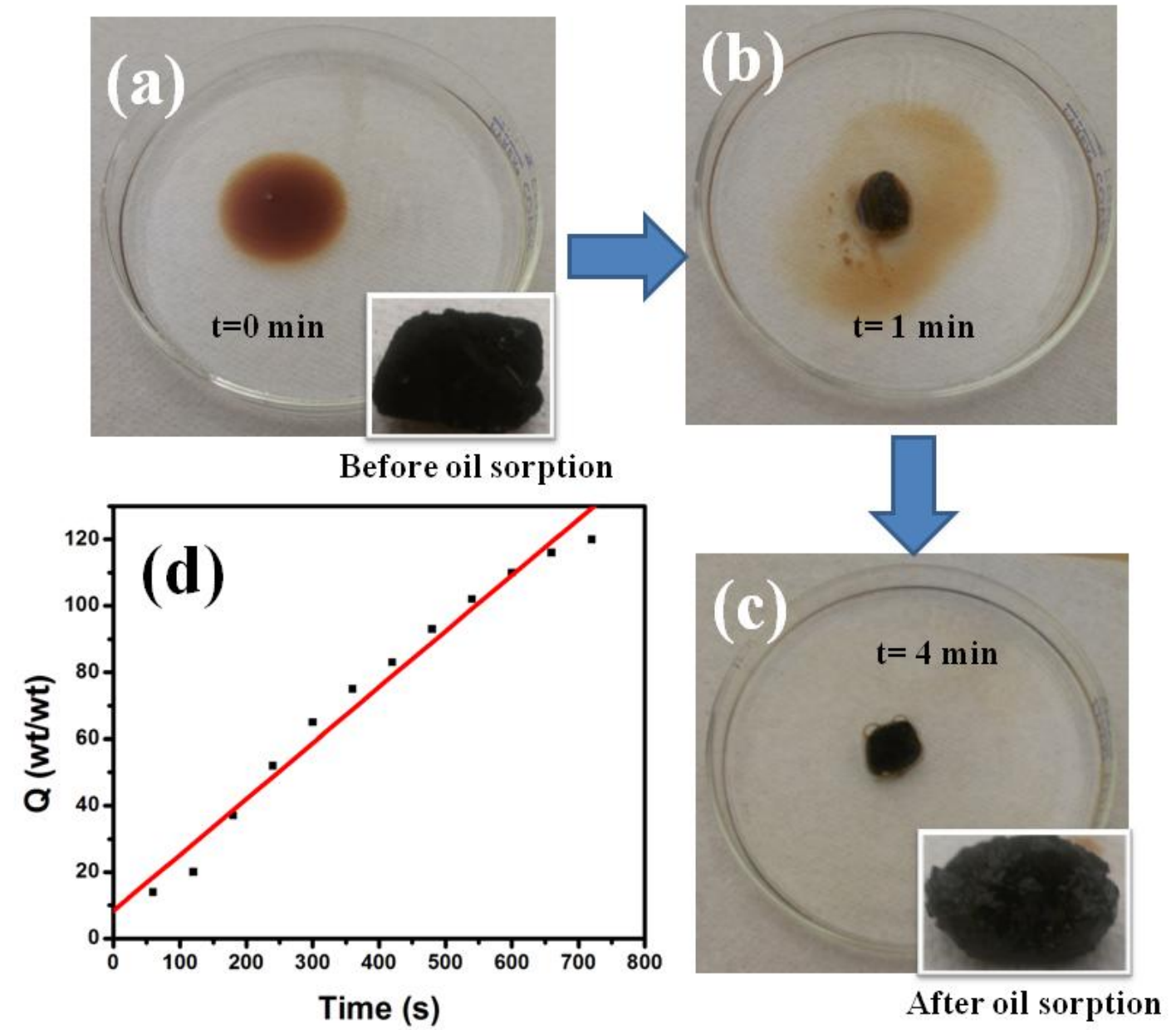

Figure 6. (a) Photograph of oil-water batch at $t=0$ min and inset shows $3 \mathrm{D}-\mathrm{CNT}$ solid structure before use, (b) 3D-CNT solid absorbing oil at $\mathrm{t}=1 \mathrm{~min}$, (c) 3D-CNT solid absorbing oil at $\mathrm{t}=4 \mathrm{~min}$, (d) weight-to-weight oil absorption capacity of the 3D-CNT solid structure.

KEYWORDS: Carbon nanotubes, chemical cross-linking, Suzuki reaction, three-dimensional, Palladium catalyst

Sehmus Ozden, Tharangattu N. Narayanan, Chandra S. Tiwary, Pei Dong, Amelia H. C. Hart, Robert Vajtai, Pulickel M. Ajayan ${ }^{*}$

Title: 3D Macroporous Solids from Chemically Cross-linked Carbon Nanotubes 


\section{WILEY-VCH}

\section{Supporting Information}

\section{D Macroporous Solids from Chemically Cross-linked Carbon Nanotubes}

Sehmus Ozden ${ }^{1}$, Tharangattu N. Narayanan ${ }^{2}$, Chandra S. Tiwary ${ }^{1}$,Pei Dong ${ }^{1}$, Amelia H. C.

$$
\text { Hart }^{1}, \text { Robert Vajtai }{ }^{1} \text {,Pulickel M. Ajayan }{ }^{1 *}
$$

\section{Synthesis of 3D-CNT Solid Macrostructure}

CNTs $(12 \mathrm{mg})$ were refluxed in concentrated $\mathrm{HNO}_{3}$ for 12 hours to produce shortened and oxidized CNTs, which are terminated with oxygen-containing groups, mainly carboxyl groups. Oxidized CNTs washed with DI-water until $\mathrm{pH}=7$. Then CNTs were refluxed in $30 \mathrm{ml} \mathrm{SOCl}_{2}$ and $2 \mathrm{ml} \mathrm{1,2-dichlorobenzene} \mathrm{for} 24$ hours. CNT and CNT was sonicated $10 \mathrm{~min}$ and added to flask. $60 \mathrm{mg} \mathrm{Pd}\left(\mathrm{PPh}_{3}\right)_{4}$ and $160 \mathrm{mg} \mathrm{Cs} \mathrm{CO}_{3}$ was added in toluene $(30 \mathrm{ml})$. The reaction was run at $100{ }^{\circ} \mathrm{C}$, for 144 hours under Ar atmosphere. The final product dispersed in DI-water and freeze dried.
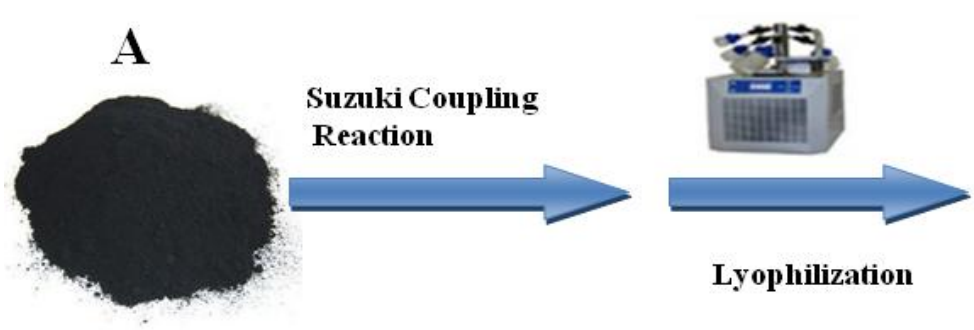

B
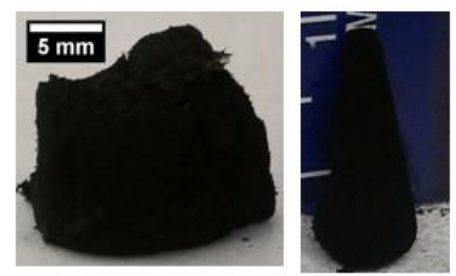

Figure S1. Photograph of (A) pristine CNT powder, (B) 3D-CNT solid structure after Suzuki coupling reaction and lyophilization. 


\section{WILEY-VCH}

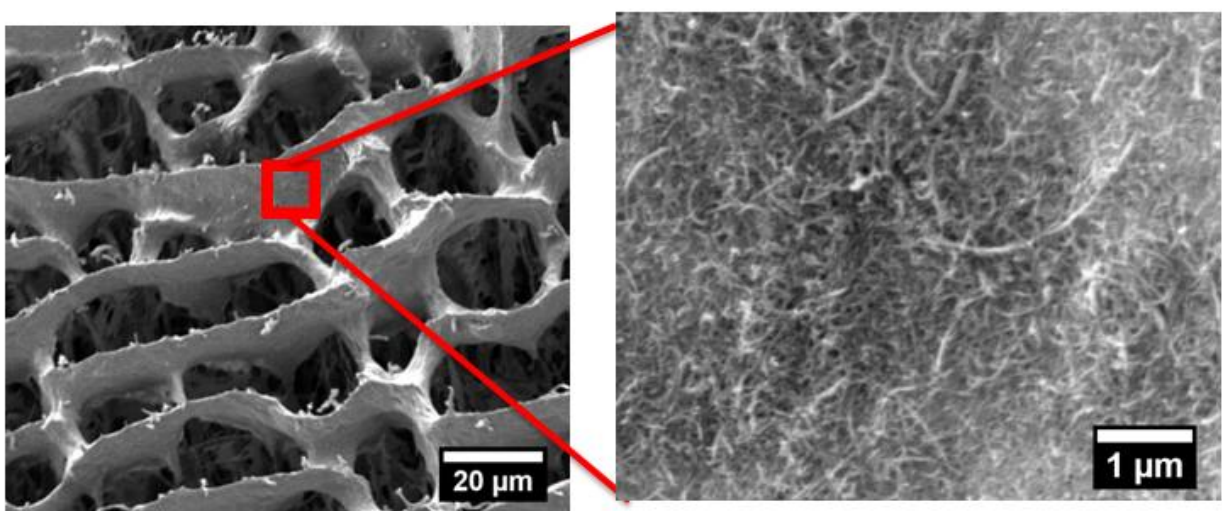

Figure S2. Scanning electron microscope (SEM) images of porous 3D-CNT solid macrostructure. CNTs formed like layered sheets.
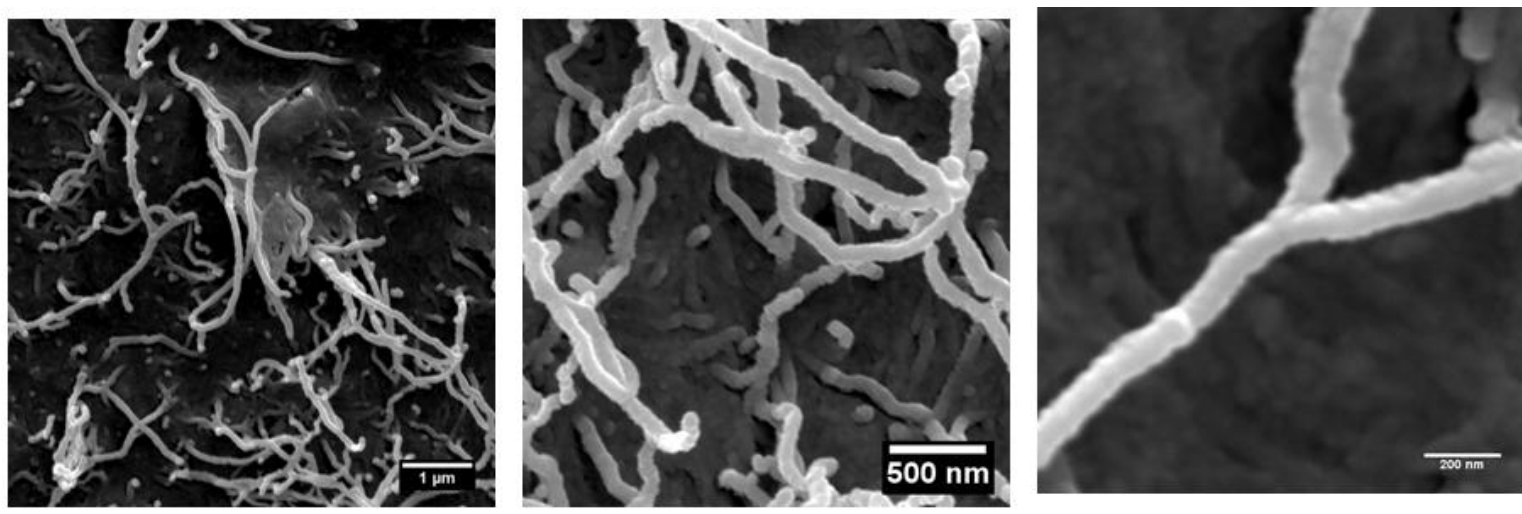

Figure S3. Scanning electron microscope (SEM) images of CNT network/junctions after Suzuki coupling reaction.
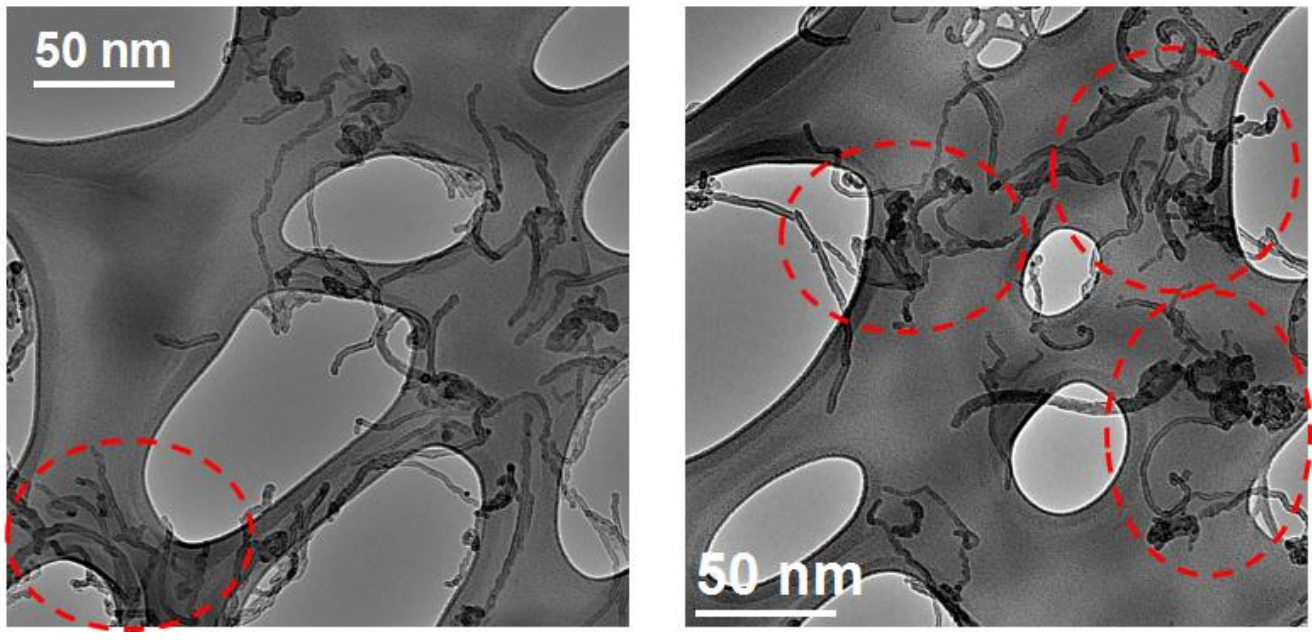

Figure S4. Transmission electron microscope (TEM) of 3D-CNT network. 


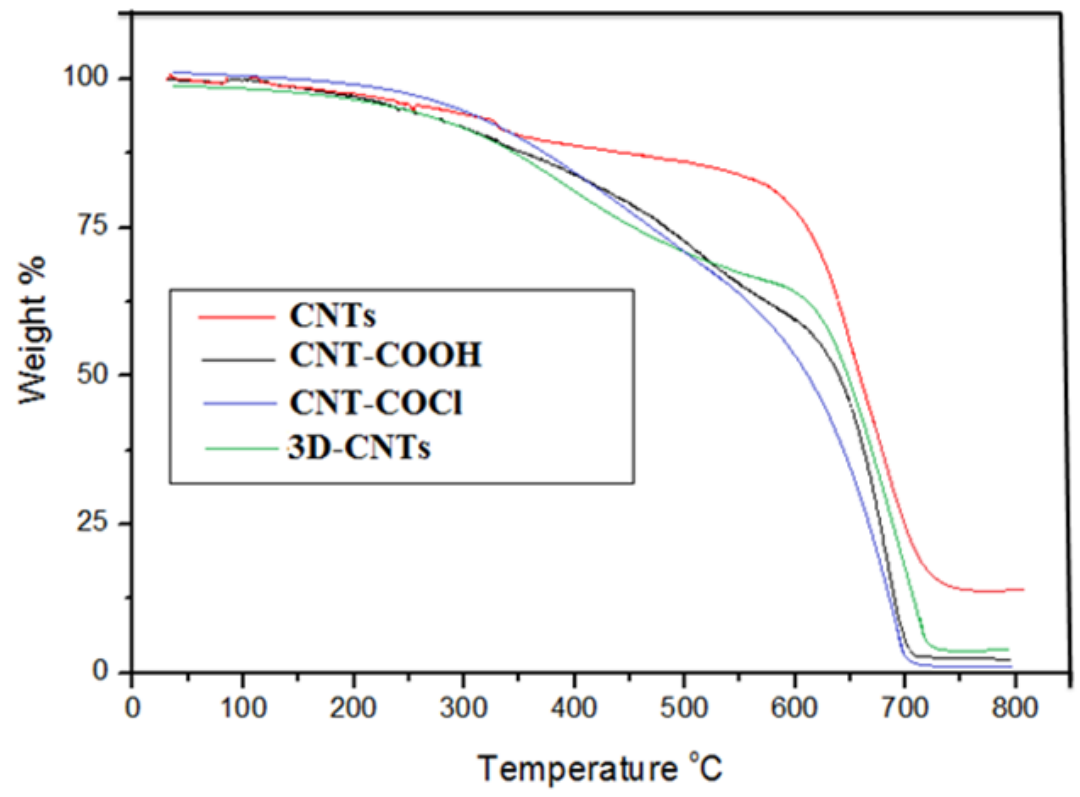

Figure S5. Thermogravimetric analysis graph (TGA) of pristine, oxidized, chlorinated CNTs and 3D-CNTs.
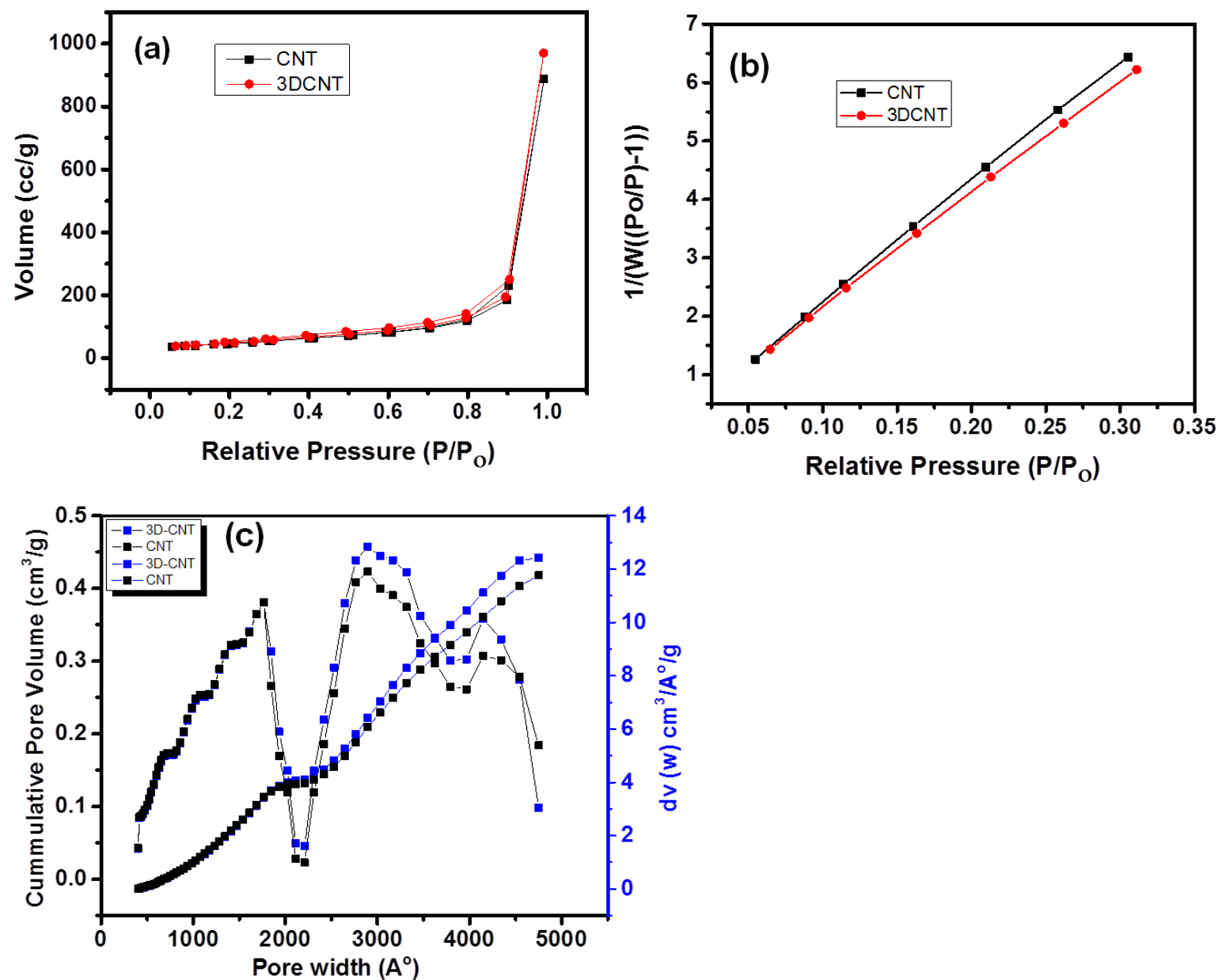

Figure S6. (a) The $\mathrm{N}_{2}$ - absortion isotherm of pristine CNTs and 3D-CNT solid (b) BET

$\underline{\text { Surface area of Pristine CNTs and 3D-CNT solid (c) DFT method pore size distribution and }}$ 


\section{WILEY-VCH}

cumulative pore volume of pristine CNTs and 3D-CNT solids. (BET surface analysis has been done after freeze drying of pristine CNTs and 3D-CNT solids) 
Production Data
Click here to download Production Data: Figures with Captions.docx

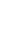

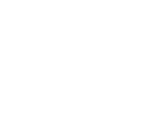

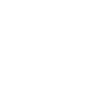
.

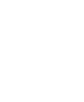
. .

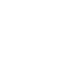

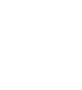

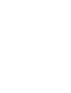

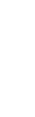
. 更 更 更 更 更 更 更 更 更 更 更 更 更 更 更 更

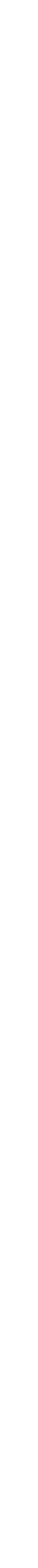

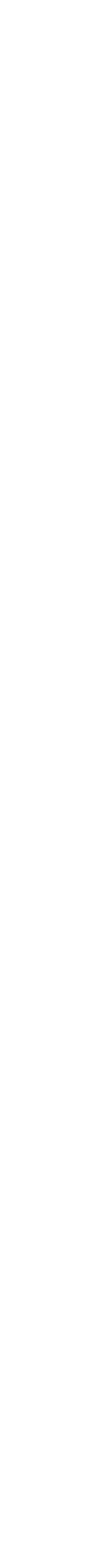
(1) 